\title{
Physical mapping of restriction fragment length polymorphisms (RFLPs) in homoeologous group 7 chromosomes of wheat by in situ hybridization $\S$
}

\author{
J. M. CHEN $\dagger \&$ J. P. GUSTAFSON*‡ \\ $\dagger$ Department of Agronomy, Jiangsu Agricultural College, Yangzhou 225001, China and $\ddagger U . S . D . A .$, Agricultural Research \\ Service, Plant Genetics Research Unit, and Plant Science Unit, University of Missouri, Columbia, Missouri 65211, U.S.A.
}

\begin{abstract}
In situ hybridization with biotin-labelled DNA probes was used to determine the physical location of markers from an RFLP-based genetic map of homoeologous group 7 in wheat (Triticum aestivum L.). The observed results indicated all probes hybridized to the corresponding group 7 chromosomes of all three wheat genomes and that the gene orders on the physical map were basically the same as that of the RFLP-based genetic map. The distance for each marker from the centromere on the physical map was different from those shown on the genetic map. Comparison of the genetic distance and the physical distance between two pairs of markers (Xpsr129 to Xpsr121, and Xpsr129 to Xpsr117) showed that the region between Xpsr129 and Xpsr121 contains a potential 'hot' spot of recombination on the chromosome arm. There appears to be considerable differences in crossing-over along the chromosomes. Most of the polymorphic markers are physically located in the middle portion of the chromosome arm to which they were genetically located, indicating reduced recombination in the centromeric and telomeric regions. Markers on the physical map were located outside the C-banded regions. The translocation break point involving 7BS and a colinear relationship among the homoeologous group 7 chromosomes are discussed.
\end{abstract}

Keywords: biotin, in situ hybridization, labelling, RFLPs, Triticum aestivum.

\section{Introduction}

One important endeavour of plant genetic research is to create genetic maps, which could be very useful for plant geneticists and breeders. Using traditional and molecular methods, genetic maps of diploid plants were rapidly developed in contrast to polyploid plants such as hexaploid wheat (Triticum aestivum L. em Thell.). By 1987, less than 100 loci were located to wheat chromosomes; however, this number has dramatically increased in the last few years (Chao et al., 1989; Sharp et al., 1989; Devos et al., 1992). The main reasons for slow progress are the relatively large number of wheat chromosomes, the hexaploid genome

*Correspondence.

§This paper reports the results of research only; mention of a proprietary product does not constitute an endorsement or a recommendation for its use by the USDA or the University of Missouri. This paper is a contribution of the U.S. Department of Agriculture, Agricultural Research Service, and Missouri Agricultural Experimental Station, Journal Series No. 11,888. constitution and genome homoeology, which tend to result in the phenotypic masking of spontaneous and artificially induced recessive mutations. These characteristics of polyploidy have hampered and will continue to hamper the progress of genetic mapping in wheat.

Recently, restriction fragment length polymorphisms (RFLPs) have provided a powerful tool for constructing genetic maps both in animals and plants. RFLPbased genetic maps have been created in rice (Oryza sativa L.) (McCouch et al., 1988; Tanksley et al., 1989), maize (Zea mays L.) (Helentjaris et al., 1986), barley (Hordeum vulgare L.) (Graner et al., 1991; Heun et al., 1991), rye (Secale cereale L.) (Wang et al., 1991; Devos et al., 1992) and tomato (Lycopersicon esculentum L.) (Bonierbale et al., 1988). Chao et al. (1989) first completed an RFLP-based genetic map of homoeologous group 7 in wheat. Later, Devos et al. (1992) reported the RFLP-based genetic maps of homoeologous group 3.

The RFLP-based genetic maps state the distance between two markers based on genetic recombination. 
However, many have found that the distances stated on genetic maps differ from those observed on physical maps (Phillips, 1969; Rick, 1971; Ganal et al., 1989; Gustafson et al., 1990; Wang et al., 1991; Gustafson \& Dillé, 1992). In some cases, the distance between two genes can be close on a genetic map, but becomes much larger when located on a physical map, or vice versa. It is becoming increasingly important to construct physical maps of chromosomes for manipulation in plant genetics and breeding. C-banding, which locates heterochromatic C-bands on chromosomes, has recently been used for physical mapping in plants (Curtis \& Lukaszewski, 1991; Friebe et al., 1992). Combining Southern analysis with the C-banding of a series of deletion lines made possible the initial construction of a cytogenetically based physical map of RFLP loci in wheat by the assigning of RFLP markers to a chromosome arm location (Werner et al., 1992).

In situ hybridization (ISH) techniques have recently been used to identify unique DNA sequences to chromosomal regions and allow for the integration of the physical relationship of the centromere and telomeres with molecular markers on the chromosomes of any species. However, it should be noted that the cytological distances are only approximate on a molecular scale, because any detection label can be large enough to cover up to one million base pairs or more. In plants, the technique has been used to identify the chromosome hybridization sites of a number of highly repeated and low-copy sequences. For example, the 5S rDNA and the 18S.26S multigene rDNA families have been mapped in wheat (Mukai et al., 1990, 1991), and telomeres and gene loci in barley and rye (Clark et al., 1989; Gustafson et al., 1990; Schwarzacher \& HeslopHarrison, 1991; Leitch \& Heslop-Harrison, 1992; Lehfer et al., 1993). The use of ISH in mapping small repeated sequences or low-copy sequences has recently been extensively developed for use in plants (Rayburn et al., 1985; Lapitan et al., 1986; Gustafson et al., 1988, 1990; Huang et al., 1988; Clark et al., 1989; Schwarzacher \& Heslop-Harrison, 1991; Gustafson \& Dillé, 1992; Leitch \& Heslop-Harrison, 1992; Ricroch et al., 1992; Xu \& Kasha, 1992). By modifying the technique, Gustafson et al. (1990) and Gustafson \& Dillé (1992) have been able physically to locate unique sequence RFLP markers to rye and rice chromosomes.

about genome organization and confidence in creating high-resolution physical maps by in situ hybridization. The present study was undertaken to map physically the RFLP markers of homoeologous group 7 of wheat using in situ hybridization, and to compare the genetic and physical maps.

\section{Materials and methods}

\section{Plants and probes}

T. aestivum cv. Chinese Spring, and Chinese Spring ditelosomic lines involving both arms of 7A, 7B and $7 \mathrm{D}$, were supplied by the USDA-E. R. Sears Wheat Genetic Stock Collection. All of the ditelosomic stocks were cytologically checked by C-banding for deletions or other structural changes before being used. The RFLP clones used were from the map of Chao et al. (1989) and were supplied by Dr M. D. Gale (John Innes Centre, Norwich, UK). The DNA clones were inserted in plasmid pUC18 and ranged in size from $0.5-1.2 \mathrm{~kb}$ (see Table 1 ). The $\alpha$-amylase 2 gene (clone $4868, \alpha-A m y 2$ ) inserted in pBR322 was supplied by D. C. Baulcombe (John Innes Centre, Norwich, U.K.).

\section{Preparation of slides}

The protoplast preparation followed the technique developed by Dillé et al. (1990) with some modification. Seeds were germinated in Petri dishes on moist filter paper. Root tips (1.5-2.5 cm long) were cut and placed in water at $4^{\circ} \mathrm{C}$ for 20 to $24 \mathrm{~h}$. Pretreated root tips were fixed in ethanol-glacial acetic acid $(3: 1 \mathrm{v} / \mathrm{v})$ at $4^{\circ} \mathrm{C}$ overnight. The root tips were transferred to distilled water for $15 \mathrm{~min}$ and then hydrolysed in $0.2 \mathrm{~N}$ $\mathrm{HCl}$ for $40 \mathrm{~min}$ at room temperature. The root tips were then digested with 1 per cent cellulase and 3 per cent pectolyase (Karlan) mixture for 30-40 min at room temperature. The meristems were scraped out and squashed gently in 45 per cent acetic acid onto the slide. Good slides were immediately frozen with dry ice to remove the cover slip. Slides were air-dried for $1 \mathrm{~h}$ and transferred to a desiccator overnight. Slides were then stored at $-80^{\circ} \mathrm{C}$ until used for hybridization (from one week to three months).

\section{In situ hybridization}

Nick translation of DNA probes with biotin-11-dUTP (Enzo) and hybridization of biotinylated probes to the chromosome preparations, except the hybridization temperature, followed the method of Gustafson et al. (1990). The chamber containing the slides was placed in an oven at $90^{\circ} \mathrm{C}$ for $10 \mathrm{~min}$ to denature the chromosomal and probe DNA again. The chamber was then transferred to a $42^{\circ} \mathrm{C}$ incubator for overnight hybridization. In general, hybridization time was approximately $20 \mathrm{~h}$. 
Table 1 Probes (cDNA clones) used in this study

\begin{tabular}{lll}
\hline Probe & \multicolumn{1}{c}{ Location } & Insert size $(\mathrm{kb})$ \\
\hline PSR160 & 7AS,7DS & 0.5 \\
PSR119 & 7AS,7DS & 0.8 \\
PSR65 & 7AS,7BS,7DS & 0.9 \\
PSR105 & 7AL,7BL,7DL & 1.1 \\
PSR169 & 7AL,7BL,7DL & 1.2 \\
PSR117 & 7AL,7BL,7DL & $0.8,0.2$ \\
PSR129 & 7AL,7BL,7DL & 1.2 \\
PSR121 & 7AL,7BL,7DL & 1.1 \\
\hline
\end{tabular}

\section{Detection of hybridization}

After hybridization, the slides were subjected to a series of washes. The slides were washed in $2 \times$ SSC at room temperature for $5 \mathrm{~min}, 25$ per cent formamide/ $2 \times \mathrm{SSC}$ at $42^{\circ} \mathrm{C}$ for $10 \mathrm{~min}, 2 \times \mathrm{SSC}$ at $37^{\circ} \mathrm{C}$ for 15 $\mathrm{min}, 2 \times \mathrm{SSC}$ at room temperature for $5 \mathrm{~min}$, and 0.1 per cent Triton-X in phosphate buffered saline (PBS) at room temperature for $4 \mathrm{~min}$. The last wash was in PBS for $5 \mathrm{~min}$ at room temperature. The rest of the steps were the same as in Gustafson et al.(1990).

\section{Physical mapping}

During observation under phase-contrast, biotin labelling could be found both on telosomics and on complete chromosomes. When identifying the complete chromosome, it was necessary to distinguish each member of homoeologous group 7 according to the size and the arm ratio. The arm lengths of each labelled chromosome were measured from a high-resolution television screen with electronic calipers. The probe hybridization site on the complete chromosome was always compared with that observed on the appropriate ditelosomic line in order to eliminate any false identification of the hybridization site. All measurements, including the physical location of the hybridization site, were taken from the centromere. From these measurements, the probe location as a percentage distance from the centromere to the hybridization site over the total arm length was calculated. The location of the hybridization site for each probe resulted from a minimum of 10 measurements from both telosomic and complete chromosomes in different nuclei.

Photographs were taken with Zeiss phase-contrast $63 \times$ or $100 \times$ (oil) objectives, using Kodak technical Pan film 2415.

\section{Results and discussion}

All of the ditelosomic stocks for every arm of homoeologous group 7 were C-banded prior to using them for in situ hybridization in order to locate and visualize any potential chromosome alterations in the ditelosomic stocks that were not present in the complete chromosome. Since no visible alterations were detected all of the stocks were used in the following analyses.

The present study utilized cDNA clones as probes from the RFLP-based genetic map of wheat homoeologous group 7 which covered both the long and short arms (Chao et al., 1989). Because the ditelosomics of wheat homoeologous group 7 were included in this study, the physical location to which a probe hybridized could be easily identified to an individual chromosome arm. Sometimes, a labelled complete homoeologous chromosome and a labelled telosomic chromosome were observed in the same cell. The previously established arm ratio and chromosome sizes were used to identify complete chromosomes (Gill et al., 1991a). The arm ratios of 7A, 7B and 7D are 1.0, 1.5 and 1.1, respectively. Chromosomes 7A and 7D are similar in arm ratios, but they are easily identified as $7 \mathrm{~A}$ is much larger than $7 \mathrm{D}$. The labelled chromosomes of homoeologous group 7 were, therefore, readily distinguished in either complete or incomplete cells. The results showed that all RFLP probes hybridized to the corresponding group 7 chromosomes of all three genomes (Fig. 1 and Table 2). This was consistent with the hexaploid constitution of wheat, where a homoeologous relationship among the three genomes exists. The data confirmed those of Chao et al. (1989) in that the DNA sequences homologous to these probes were present in all three homoeologous chromosomes. The RFLP hybridization sites mapped using the telosomic lines were identical to the complete chromosomes (Fig. 1 and Table 2), indicating that the identification of the chromosomes of homoeologous group 7 by their arm ratios and size was possible.

The RFLP order shown in Table 2 was basically the same as that of the RFLP-based genetic map (Chao et al., 1989). The change in the physical order of Xpsr117 and Xpsr169 on chromosome 7B as compared to the order on chromosomes $7 \mathrm{~A}$ and $7 \mathrm{D}$, was probably caused by their very close hybridization sites on the chromosome resulting in the possibility of an error being made in measuring the physical distance. Table 2 shows that the hybridization sites for Xpsr117 and $X p s r 169$ were very close together and that the standard errors overlap (33.1 per cent \pm 3.1 and 32.9 per cent \pm 4.6 on $7 \mathrm{BL}$, respectively).

The discrepancy between the physical location of $\alpha$-amylase and Xpsr 117 is harder to explain. In all three homoeologous chromosomes, the $\alpha$-amylase hybridi- 


\section{PSR160 PSR169}

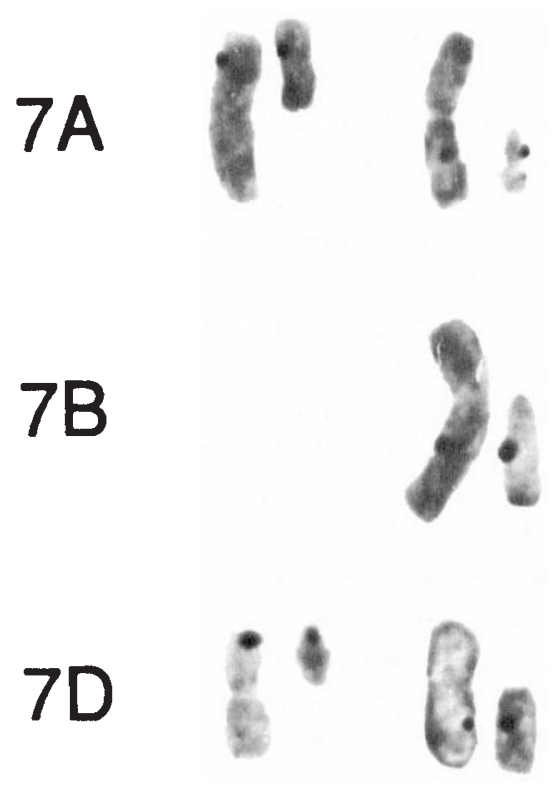

Fig. 1 In situ hybridization of two of the eight biotinlabelled probes mapped to homoeologous group 7 chromosome in wheat. Dark spots show the hybridization sites of the probes on both the telocentric and whole chromosome. None of the chromosomes or telosomes were computer image enhanced.

zation site was located between Xpsr117 and Xpsr129. The genetic maps for chromosomes $7 \mathrm{~B}$ and $7 \mathrm{D}$ have Xpsr117 located between $\alpha$-amylase and Xpsr129 (M. D. Gale, unpublished data). A possible explanation for the discrepancy is that both $\alpha$-amylase and Xpsr117 are multilocus family clones (Lazarus et al., 1985; Huttly et al., 1988), and that we physically mapped a different restriction fragment than was used in making the genetic linkage map. In addition, differential chromosome condensation may have affected the accuracy of the measurement of the hybridization site. Probes mapped close to the centromere on the genetic map, such as Xpsr65 on short arms and Xpsr105 on long arms, all mapped at about 30 per cent distance from the centromere on the physical map. Even with the presence of large $\mathrm{C}$-bands on $7 \mathrm{~B}$ and the variation in chromosome size between $7 \mathrm{~A}, 7 \mathrm{~B}$ and $7 \mathrm{D}$, the relative distances from the centromeres to the nearest markers on each of the three homoeologous chromosomes appeared to be quite similar.

Comparison of the physical map with the C-banding pattern of homoeologous group 7 chromosomes showed that all of the markers were found to be located in euchromatic regions and not in the C-band regions. In contrast, Werner et al. (1992) showed that Xpsr121 was located in the telomeric heterochromatin block on the long arm of chromosome 7A.

The present results show some differences concerning the physical hybridization sites of RFLPs within a chromosome arm as compared to the chromosome arm location observed using Southern analysis coupled with deletion mapping (Werner et al., 1992). Werner et al. (1992) showed that some RFLPs were located close to the telomeric regions whereas the present data found that the ends of the linkage maps were more interstitial. One possible explanation for the observed differences may be the fact that the processes required to create deletion stocks are widely known to cause additional chromosomal abnormalities (e.g. inversions, interstitial deletions, translocations, and duplications) (Mukai et al., 1990; Tsujimoto \& Noda, 1990; Gill et al., 1991b; Werner et al., 1992). The changes that occur when creating deletion stocks are capable of having considerable effects on probe hybridization site location without visibly changing the chromosome C-banding pattern. Endo (1988) indicated that almost half of the progeny resulting from adding a chromosome of Aegilops cylindrica $\mathrm{L}$. into wheat contained deletions and translocations, and this was the base material for creating the deletion stocks used by Werner et al. (1992). Werner et al. (1992) also suggested that the reverse order in mapping Xpsr72 and Xpsr169 on chromosome 7B could result from either a double break and inversion formed during the stock creation, or from a pre-existing inversion in the parent line. Also the deletions need to be large in order to be accurately detected using C-banding, therefore several megabases of DNA could be included in the deletion, which would result in an approximation of the physical location of the RFLP, because the RFLP could be located anywhere within the deleted region. Regardless, both techniques agree with the arm location of the analysed RFLP markers, but differ in the within-arm location of their hybridization sites. More work needs to be done before these differences can be explained.

Distances between markers on the physical map were (in some cases) different from those shown on the genetic map (Fig. 2). The results were consistent with those observed utilizing other plant and animal species in that the genetic distance in $\mathrm{cM}$ does not necessarily translate to the same physical distance in base pairs. A discrepancy between the genetic and physical map occurred at the region between probes Xpsr129 and Xpsr121. The genetic distance on chromosomes 7B and 7D showed a $>50 \mathrm{cM}$ distance from $X p s r 129$ to $X p s r 121$, while the physical distance in this region was similar in size to the adjacent region involving Xpsr117 and Xpsr129, which were separated by a genetic distance of $12 \mathrm{cM}$. This indicates that the region 
Table 2 Arm ratio $( \pm$ SE) and average probe location $( \pm S E)$ in percentage for wheat homoeologous group 7 chromosomes

\begin{tabular}{|c|c|c|c|c|}
\hline Probe & $\begin{array}{l}\text { Chromosome } \\
\text { location }\end{array}$ & $\begin{array}{c}\text { No. of } \\
\text { detections }\end{array}$ & Arm ratio & $\begin{array}{c}\text { Probe location } \\
(\%)\end{array}$ \\
\hline PSR160 & $\begin{array}{c}\text { 7A } \\
\text { 7AS } \\
\text { 7D } \\
7 \mathrm{DS}\end{array}$ & $\begin{array}{r}3 \\
11 \\
7 \\
4\end{array}$ & $\begin{array}{l}1.01 \pm 0.02 \\
1.10 \pm 0.04\end{array}$ & $\begin{array}{l}70.6 \pm 3.1 \\
69.3 \pm 3.6 \\
69.0 \pm 2.7 \\
68.6 \pm 4.7\end{array}$ \\
\hline PSR119 & $\begin{array}{c}\text { 7A } \\
\text { 7AS } \\
7 \mathrm{D} \\
7 \mathrm{DS}\end{array}$ & $\begin{array}{r}8 \\
8 \\
10 \\
8\end{array}$ & $\begin{array}{l}1.02 \pm 0.01 \\
1.12 \pm 0.04\end{array}$ & $\begin{array}{l}61.7 \pm 3.3 \\
61.3 \pm 4.3 \\
61.7 \pm 5.8 \\
64.2 \pm 4.5\end{array}$ \\
\hline PSR65 & $\begin{array}{c}7 \mathrm{~A} \\
7 \mathrm{AS} \\
7 \mathrm{~B} \\
7 \mathrm{BS} \\
7 \mathrm{D} \\
7 \mathrm{DS}\end{array}$ & $\begin{array}{r}10 \\
8 \\
12 \\
5 \\
10 \\
6\end{array}$ & $\begin{array}{l}1.03 \pm 0.03 \\
1.47 \pm 0.08 \\
1.10 \pm 0.04\end{array}$ & $\begin{array}{l}29.5 \pm 4.1 \\
28.1 \pm 3.2 \\
29.8 \pm 2.2 \\
28.6 \pm 3.9 \\
30.0 \pm 3.4 \\
27.8 \pm 4.5\end{array}$ \\
\hline PSR105 & $\begin{array}{c}7 \mathrm{~A} \\
7 \mathrm{AL} \\
7 \mathrm{~B} \\
7 \mathrm{BL} \\
7 \mathrm{D} \\
7 \mathrm{DL}\end{array}$ & $\begin{array}{r}11 \\
3 \\
14 \\
7 \\
7 \\
1\end{array}$ & $\begin{array}{l}1.01 \pm 0.01 \\
1.44 \pm 0.05 \\
1.10 \pm 0.03\end{array}$ & $\begin{array}{l}26.5 \pm 3.4 \\
25.8 \pm 5.4 \\
24.6 \pm 5.1 \\
25.2 \pm 2.8 \\
28.7 \pm 3.3 \\
30.8\end{array}$ \\
\hline PSR169 & $\begin{array}{c}7 \mathrm{~A} \\
7 \mathrm{AL} \\
7 \mathrm{~B} \\
7 \mathrm{BL} \\
7 \mathrm{DL}\end{array}$ & $\begin{array}{l}6 \\
4 \\
4 \\
4 \\
6\end{array}$ & $\begin{array}{l}1.02 \pm 0.03 \\
1.40 \pm 0.03\end{array}$ & $\begin{array}{l}31.4 \pm 4.0 \\
30.5 \pm 2.4 \\
36.0 \pm 0.7 \\
32.9 \pm 4.6 \\
31.8 \pm 2.4\end{array}$ \\
\hline PSR117 & $\begin{array}{c}7 \mathrm{~A} \\
7 \mathrm{AL} \\
7 \mathrm{~B} \\
7 \mathrm{BL} \\
7 \mathrm{DL}\end{array}$ & $\begin{array}{r}10 \\
1 \\
4 \\
5 \\
6\end{array}$ & $\begin{array}{l}1.01 \pm 0.02 \\
1.46 \pm 0.10\end{array}$ & $\begin{array}{l}33.8 \pm 2.4 \\
32.0 \\
33.8 \pm 2.3 \\
33.1 \pm 3.1 \\
33.7 \pm 2.1\end{array}$ \\
\hline PSR129 & $\begin{array}{c}7 \mathrm{~A} \\
7 \mathrm{AL} \\
7 \mathrm{~B} \\
7 \mathrm{BL} \\
7 \mathrm{D} \\
7 \mathrm{DL}\end{array}$ & $\begin{array}{l}7 \\
5 \\
7 \\
6 \\
6 \\
4\end{array}$ & $\begin{array}{l}1.04 \pm 0.03 \\
1.49 \pm 0.07 \\
1.11 \pm 0.04\end{array}$ & $\begin{array}{l}46.7 \pm 4.0 \\
41.2 \pm 3.3 \\
46.5 \pm 6.1 \\
52.6 \pm 2.5 \\
44.6 \pm 3.7 \\
39.3 \pm 4.6\end{array}$ \\
\hline$\alpha$-Amylase & $\begin{array}{c}7 \mathrm{~A} \\
7 \mathrm{AL} \\
7 \mathrm{~B} \\
7 \mathrm{BL} \\
7 \mathrm{D} \\
7 \mathrm{DL}\end{array}$ & $\begin{array}{l}5 \\
9 \\
8 \\
5 \\
6 \\
5\end{array}$ & $\begin{array}{l}1.06 \pm 0.05 \\
1.42 \pm 0.09 \\
1.15 \pm 0.03\end{array}$ & $\begin{array}{l}42.2 \pm 5.0 \\
39.0 \pm 4.8 \\
42.7 \pm 4.6 \\
39.0 \pm 6.6 \\
41.3 \pm 3.1 \\
41.6 \pm 2.0\end{array}$ \\
\hline PSR121 & $\begin{array}{c}7 \mathrm{~A} \\
7 \mathrm{AL} \\
7 \mathrm{~B} \\
7 \mathrm{BL} \\
7 \mathrm{D} \\
7 \mathrm{DL}\end{array}$ & $\begin{array}{r}15 \\
3 \\
4 \\
4 \\
7 \\
14\end{array}$ & $\begin{array}{l}1.01 \pm 0.02 \\
1.47 \pm 0.08 \\
1.08 \pm 0.04\end{array}$ & $\begin{array}{l}63.3 \pm 4.5 \\
63.9 \pm 7.4 \\
61.4 \pm 5.2 \\
63.5 \pm 1.6 \\
61.7 \pm 3.6 \\
61.5 \pm 4.2\end{array}$ \\
\hline
\end{tabular}






Fig. 2 A comprehensive picture showing physical map, the $\mathrm{C}$-banding pattern (from Gill et al., 1991a) and RFLP-based genetic map (from Chao et al., 1989) for homoeologous group 7 chromosomes in wheat. Shaded clone numbers mean that the probes are physically mapped. between Xpsr129 and Xpsr121 is a potential recombination hot spot as compared to the region between Xpsr117 and Xpsr129.

Naranjo et al. (1987) provided the cytological evidence that the short arm of $7 \mathrm{~B}$ has a small portion translocated to the long arm of $4 \mathrm{~A}$. The translocation breakpoint on 7BS is located between the locus controlling anthocyanin pigmentation $(P c)$ and the Xpsr119 in the genetic maps (Chao et al., 1989). The present results agree that there is a translocation involving the short arm of chromosome $7 \mathrm{~B}$, because Xpsr119 and Xpsr160 were not present on 7BS, but were detected on 7AS and 7DS. It has been estimated that the translocation break point is about 60 per cent of the distance from the centromere to the telomere on 7BS based on the homoeologous relationship of the three chromosomes. The present data showed a colinear relationship among the homoeologous group 7 chromosomes (Table 2 and Fig. 2). It is well known that bread wheat originated from three different species of Triticeae that evolved from a common ancestor through a long period of evolution. Genes and DNA sequences of homoeologous chromosomes in the three genomes are well known to be triplicated and show a high degree of synteny. Therefore, the regions of recombination could be similar within the homoeologous chromosomes regardless of their size. The large amount of heterochromatin present on $7 \mathrm{~B}$ vs. that on 
7A and 7D does not appear to have any effect on recombination between the genes located on those chromosomes. Therefore, the heterochromatin present in the B-genome chromosome 7B may not hinder the activities of recombination, thus allowing it to be conserved during the evolution of wheat.

It is most interesting to note that all of the RFLP markers physically mapped tend to cluster intercalarily on either the short or long arms of all chromosomes of homoeologous group 7 (Fig. 2). The regions near the centromeres contain no RFLP markers. This is supported by observations utilizing both genetic and physical mapping (Curtis \& Lukaszewski, 1991; Devos et al., 1992; Leitch \& Heslop-Harrison, 1992; Weide et al., 1993). However, the fact that ISH showed that the distal 30 per cent of all arms of homoeologous group 7 also lacked RFLP markers was surprising. Even with the greatly expanded wheat genetic map that exists today, many of the physically mapped clones used in this study are still located at the end of the current linkage maps (M. D. Gale, personal communication). Considerable variation is known to occur in crossingover within chromosomes of plant or animal genomes. Regions corresponding to centromeres and even some telomeres in tomato and potato show a 10-fold decrease in recombination as compared to other regions in the genome and that only 28 per cent of the mapped loci are located to regions of suppressed recombination (Tanksley et al., 1992). The high density of markers that are genetically mapped to specific regions probably indicates regions of lower levels of recombination. This has also been seen in Drosophila where high levels of suppression of recombination are seen near the centromere (Roberts, 1965). This negative effect on crossing-over termed 'centromere effect' or 'spindle effect' by Beadle (1932) and Mather (1938) has also been demonstrated in yeast by Lambie \& Roeder (1986) and in tomato by Ganal et al. (1989). However, it is suggested that the presence of heterochromatin near the centromere can also suppress recombination. In addition to the suppressed regions of recombination near centromeres, Lefevre (1971) showed that recombination frequencies were directly correlated with salivary gland chromosome banding patterns and that suppressed regions were also observed near some telomeres in Drosophila.

The lack of RFLP detection sites at the homoeologous group 7 chromosome telomeres is harder to explain. The lack of recombination at the telomeres of the wheat chromosomes of homoeologous group 7 could result from some degree of similarity with the centromeric regions. Lefevre (1970) indicated that some chromosomes in Drosophila showed a suppression of recombination at the telomeres. Meyne $e t$ al. (1990) determined the distribution of nontelomeric sites of the (TTAGGG) $)_{n}$ telomeric sequence in vertebrate species and found that the most common nontelomeric location was at or near the centromere region. A recent study showed that minor satellite DNA sequences associated with mouse centromeres were also located so close to the telomeres that they were present on the same fragment as the (TTAGGG) sequence (Kipling et al., 1991). Regardless of the reason, it is obvious that areas showing high and low levels of polymorphism correspond to areas of high and low levels of recombination and that these regions exist in wheat as they do in animals and other plants. A great deal more mapping is necessary in order to establish the extent of these regions in the genomes that make up hexaploid wheat.

\section{Acknowledgements}

The authors thank Dr S. Chao, K. Ross and M. Wanous for critical reading of the manuscript. The authors also thank Z. M. Zhou, K. Houchins and P. G. Goicoechea for their kind help throughout the study.

\section{References}

BEADLE, G. W. 1932. A possible influence of the spindle fibre on crossing-over in Drosophila. Proc. Natl. Acad. Sci. U.S.A., 18, 160-165.

BONIERBALE, M. W., PLAISTED, R. L. AND TANKSLEY, S. D. 1988. RFLP maps based on a common set of clones reveal models of chromosomal evolution in potato and tomato. Genetics, 120, 1095-1103.

CHAO, S., SHARP, P. J., WORLAND, A. J., WARNAM, E. J., KOEBNER, R. M. D. AND GALE, M. D. 1989. RFLP-based genetic maps of wheat homoeologous group 7 chromosomes. Theor. Appl. Genet., 78, 495-504.

CLARK, M., KARP, A. AND ARCHER, s. 1989. Physical mapping of the B-hordein loci on barley chromosome 5 by in situ hybridization. Genome, 32, 925-929.

CURTIS, C. A. AND LUKASZEwsKI, A. J. 1991. Genetic linkage between C-bands and storage protein genes in chromosome 1B of tetraploid wheat. Theor. Appl. Genet., 81, 245-252.

DEVOS, K. M., ATKINSON, M. D., CHINOY, C. N., LIU, C. J. AND GALE, M. D. 1992. RFLP-based genetic map of the homoeologous group 3 chromosomes of wheat and rye. Theor. Appl. Genet., 83, 931-939.

DILlE, J. E., BITTEL, D. C., ROSS, K. AND GUSTAFSON, J. P. 1990. Preparing plant chromosomes for scanning electron microscopy. Genome, 33, 333-339.

ENDO, T. R. 1988. Induction of chromosomal structural changes by a chromosome of Aegilops cylindrica L. in common wheat. J. Hered., 79, 336-370.

FRIEBE, B., MUKAI, Y., GILL, B. S. AND CAUDERON, Y. 1992. C-banding and in-situ hybridization analyses of Agropyron inter- 
medium, a partial wheat $\mathrm{x}$ Agropyron intermedium amphiploid, and six derived chromosome addition lines. Theor. Appl. Genet., 84, 899-905.

GANAL, M. W., YounG, N. D. AND TANKSLEY, S. D. 1989. Pulsed field gel electrophoresis and physical mapping of large DNA fragments in the $\mathrm{Tm}-2 \mathrm{a}$ region of chromosome 9 in tomato. Mol. Gen. Genet., 215, 395-400.

GILL, B. S., FRIEBE, B. AND ENDO, T. R. 1991a. Standard karyotype and nomenclature system for description of chromosome bands and structural aberrations in wheat (Triticum aestivum). Genome, 34, 830-839.

GILL, K. S., LUBbERS, E. L., GILL, B. S., RAUPP, W. J. AND COX, T. S. 1991b. A genetic linkage map of Triticum tauschii (DD) and its relationship to the $D$ genome of bread wheat (AABBDD). Genome, 34, 362-374.

GRANER, A., JAHOOR, A., SCHONDELMAIER, J., SIEDLER, H., PILLEN, K., FISCHBECK, G., WENZEL, G. AND HERRMAN, R. G. 1991. Construction of an RFLP map of barley. Theor. Appl. Genet., 83, 250-256.

GUSTAFSON, J. P., BUTLER, E. AND McINTYRE, C. L. 1990. Physical mapping of a low-copy DNA sequence in rye (Secale cereale L.). Proc. Natl. Acad. Sci. U.S.A., 87, 1899-1902.

GUSTAFSON, J. P., DERA, A. R. AND PETROVIC, s. 1988. Expression of modified rye ribosomal RNA genes in wheat. Proc. Natl. Acad. Sci. U.S.A., 85, 3943-3945.

GUSTAFSON, J. P. AND DILLÉ, J. E. 1992. Chromosome location of Oryza sativa recombination linkage groups. Proc. Natl. Acad. Sci. U.S.A., 89, 8646-8650.

HELENTJARIS, T., SLOCUM, M., WRIGHT, S., SCHAEFER, A. AND NIENHUIS, J. 1986. Construction of genetic linkage maps in maize and tomato using restriction fragment length polymorphisms. Theor. Appl. Genet., 72, 257-264.

HEUN, M., KENNEDY, A. E., ANDERSON, J. A., LAPITAN, N. L. V., SORRELLS, M. E. AND TANKSLEY, S. D. 1991. Construction of a restriction fragment length polymorphism map for barley (Hordeum vulgare). Genome, 34, 437-447.

HUANG, P.-L., HAHLBROCK, K. AND SOMSSICH, I. E. 1988. Detection of a single-copy gene on plant chromosomes by in situ hybridization. Mol. Gen. Genet., 211, 143-147.

HUTtLY, A. K., MARTIENSSEN, R. A. AND BAULCOMBE, D. C. 1988. Sequence heterogeneity and differential expression of the $\alpha-A m y 2$ gene family in wheat. Mol. Gen. Genet., 214, 232-240.

KIPLING, D., ACKFORD, H. E., TAYLOR, B. A. AND COOKE, H. J. 1991. Mouse minor satellite DNA genetically maps to the centromere and is physically linked to the proximal telomere. Genomics, 11, 235-241.

LAMBIE, E. J. AND RODER, G. S. 1986. Repression of meiotic crossing over by a centromere (Cen 3 ) in Saccharomyces cerevisiae. Genetics, 114, 769-789.

LAPITAN, N. L. V., SEARS, R. G., RAYBURN, A. L. AND GILL, B. S. 1986. Wheat-rye translocations detection of chromosome breakpoints by in situ hybridization with a biotin-labeled DNA probe. J. Hered., 77, 415-419.

LAZARUS, C. M., BAULCOMBE, D. C. AND MARTIENSSEN, R. A. 1985. $\alpha$-amylase genes of wheat are two multigene families which are differentially expressed. Plant Mol. Biol., 5, 13-24.

LEFEVRE, G., Jr. 1971. Salivary chromosome bands and the fre- quency of crossing over in Drosophila melanogaster. Genetics, 67, 497-513.

LEHFER, H., BUSCH, W., MARTIN, R. AND HERRMANN, R. 1993. Localization of the B-hordein locus on barley chromosomes using fluorescence in situ hybridization. Chromosoma, 102, 428-432.

LEITCH, I. J. AND HESLOP-HARRISON, J. S. 1992. Physical mapping of the 18S-5.8S-26S rRNA genes in barley by in situ hybridization. Genome, 35, 1013-1018.

MATHER, K. 1938. Crossing over and heterochromatin in the $\mathrm{X}$ chromosome of Drosophila melanogaster. Genetics, 24, 413-435.

McCOUCH, S. R., KOCHERT, G., YU, Z. H., WANG, Z. Y., KHUSH, G. S., COFFMAN, W. R. AND TANKSLEY, S. D. 1988. Molecular mapping of rice chromosomes. Theor. Appl. Genet., 76, 815-829.

MEYNE, J., BAKER, R. J., HOBART, H. H., HSU, T. C., RYDER, O. A., WARD, O. G., WILEY, J. E., WURSTER-HILL, D. H., YATES, T. L. AND MOYZIS, R. K. 1990. Distribution of non-telomeric sites of the (TTAGGG) $)_{\mathfrak{n}}$ telomeric sequence in vertebrate chromosomes. Chromosoma, 99, 3-10.

MUKAI, Y., ENDO, T. R. AND GILL, B. S. 1990. Physical mapping of the $5 \mathrm{~S}$ rRNA multigene family in common wheat. $J$. Hered., 81, 290-295.

MUKAI, Y., ENDO, T. R. AND GILL, B. S. 1991. Physical mapping of the 18S.26S rRNA multigene family in common wheat: Identification of a new locus. Chromosoma, 100, 71-78.

NARANJO, T., ROCA, A., GOICOECHEA, P. G. AND GIRALDEZ, R. 1987. Arm homoeology of wheat and rye chromosomes. Genome, 29, 873-882.

PHILlips, R. L. 1969. Recombination in Zea mays L. I. Location of genes and interchanges in chromosomes 5, 6, and 7. Genetics, 61, 107-116.

RAYBURN, A. L. AND GILL, B. S. 1985. Use of biotin-labeled probes to map specific DNA sequences on wheat chromosomes. J. Hered., 76, 78-81.

RICK, C. M. 1971. Some cytogenetic features of the genome in diploid plant species. In: Kimber, G. and Redei, G. P. (eds) Stadler Genetic Symposium, pp. 153-154. University of Missouri Press, Columbia, MO.

RICROCH, A., PEFFLEY, E. B. AND BAKER, R. J. 1992. Chromosomal location of rDNA in Allium: in situ hybridization using biotin- and fluorescein-labelled probe. Theor. Appl. Genet., 83, 413-418.

ROBERTS, P. A. 1965. Difference in the behaviour of eu- and hetero-chromatin: crossing over. Nature, 205, 725-726.

SCHWARZACHER, T. AND HESLOP-HARRISON, J. S. 1991. In situ hybridization to plant telomeres using synthetic oligomers. Genome, 34, 317-323.

SHARP, P. J., CHAO, S., DESAI, S. AND GALE, M. D. 1989. The isolation, characterization and application in the Triticeae of a set of wheat RFLP probes identifying each homoeologous chromosome arm. Theor. Appl. Genet., 78, 342-348.

TANKSLEY, S. D., McCOUCH, S., YU, Z., WANG, Z. AND FULTON, S. 1989. RFLP map of rice chromosomes. Rice Genet. Newsl., 5, 128-130.

TANKSLEY, S. D., GANAL, M. W., PRINCE, J. P., DE VICENTE, M. C., BONIERBALE, M. W., BROUN, P., FULTON, T. M., GIOVANNONI, J. J., GRANDillo, S., MARTin, G. B., MESSEGUeR, R., Miller, J. C., 
MILlER, L., PATERSON, A. H., PINEDA, O., RÖDER, M. S., WING, R. A., WU, W. AND YOUNG, N. D. 1992. High density molecular linkage maps of the tomato and potato genomes. Genetics, 132, 1141-1160.

TSUJMOTO, H. AND NODA, K. 1990. Deletion mapping by gametocidal genes in common wheat: position of speltoid suppression (Q) and beta-amylase (beta-Amy-A2) genes on chromosome 5. Genome, 33, 850-853.

WANG, M. L., ATKINSON, M. D., CHINOY, C. N., DEVOS, K. M., HARCOURT, R. L., LUI, C. J., ROGERS, W. J. AND GALE, M. D. 1991. RFLPbased genetic map of rye (Secale cereale L.) chromosome 1R. Theor. Appl. Genet., 82, 174-178.
WEIDE, R., VAN WORDRAGEN, M. F., LANKHORST, R. K., VERKERK, R., HANHART, C., LIHARSKA, T., PAP, E., STAMM, P., ZABEL, P. AND KOORNNEEF, M. 1993. Integration of the classical and molecular linkage maps of tomato chromosome 6. Genetics, 135, 1175-1186.

WERNER, J. E., ENDO, T. R. AND GILL, B. S. 1992. Toward a cytogenetically based physical map of the wheat genome. Proc. Natl. Acad. Sci. U.S.A., 89, 11307-11311.

XU, J. AND KASHA, K. J. 1992. Identification of a barley chromosomal interchange using N-banding and in situ hybridization techniques. Genome, 35, 392-397. 